\title{
PENGEMBANGAN PRODUK SALA LAUAKDENGAN TEKNIK GELATINISASI
}

\author{
Elfrimo Dwi ${ }^{1}$, Anni Faridah ${ }^{2}$, Ernawati ${ }^{3}$ \\ ${ }^{123}$ Fakultas Teknik, Universitas Negeri Padang, Indonesia \\ e-mail: faridah.anni@fpp.unp.ac.id
}

\begin{abstract}
Abstrak
Sala lauak is a traditional food that is easily found in West Sumatra. The development of sala leak products is carried out by reducing oil using gelatinization techniques. The process that occurs in gelatinization is when the starch granules are given water and heat, the starch granules will expand. This study aims to (1) develop sala lauak products by gelatinization techniques on oil absorption, (2) determine the organoleptic quality of sala lauak products by gelatinization technique processes, and (3) determine the fat content of sala lauak products by gelatinization technique processes. This research method is Research and Development $(\mathrm{RnD})$. The results of this study in the organoleptic quality produced by sala lauak with pragelatinization flour showed a significant influence on the quality of inner texture, outer texture, taste, shape, and color. The same thing also happened to a significant reduction in fat content by three times lower using pregelatinized rice flour which is $7.4 \%$ compared to ordinary rice flour which is $25 \%$.
\end{abstract}

Kata kunci : Sala Lauak, Gelatinization Technique, rice flour.

\begin{abstract}
Sala lauak merupakan salah satu makanan tradisional yang mudah ditemukan di Sumatera barat. Pengembangan produk sala lauak dilakukan dengan cara pengurangan minyak dengan teknik gelatinisasi. Proses yang terjadi pada gelatinisasi yaitu ketika granula pati diberi air dan panas maka granula pati akan mengembang. Penelitian ini bertujuan untuk (1) mengembangkan produk sala lauak dengan proses teknik gelatinisasi terhadap penyerapan minyak, (2) menganalisis mutu organoleptik pada produk sala lauak dengan proses teknik gelatinisasi, dan (3) mengetahui kadar lemak terhadap produk sala lauak dengan proses teknik gelatinisasi.Metode penelitian ini adalah Research and Development (RnD). Hasil dari penelitian ini dalam mutu organoleptik yang dihasilkansala lauak dengan tepung pragelatinisasi menunjukkanadanya pengaruh signifikan terhadap kualitas tekstur dalam, tekstur luar, rasa, bentuk dan warna. Hal yang sama juga terjadi pada penurunan kadar lemak yang signifikan sebesar tiga kali lipat lebih rendah menggunakan tepung beras pragelatinisasi yaitu $7,4 \%$ dibandingkan dengan tepung beras biasa yaitu $25 \%$.
\end{abstract}

Keywords : Sala Lauak, Teknik Gelatinisasi, Tepung Beras.

\section{PENDAHULUAN}

Sala lauak merupakan salah satu makanan tradisional yang mudah ditemukan di Sumatera Barat khususnya di Pariaman. Sala lauak yang berbahan dasar tepung beras, ikan asin, bawang merah, bawang putih, cabe giling, daun kunyit, daun bawang, jahe, garam, dan air. Cara pengolahannya juga sederhana yaitu air dan bumbu di masak sampai mendidih lalu dimasukan tepung, dan di masak sampai kalis, lalu dibentuk bulat dan langsung digoreng. (Aorora, 2008: 3).
Sala lauak yang di produksi oleh penjual di Kabupaten Padang Pariaman, ada yang memakai tepung siap pakai khusus untuk membuat sala lauakdan ada juga yang memakai tepung beras. Menurut hasil wawancara yang peneliti lakukan pada bulan Agustus 2018 dengan pengusaha tepung sala lauaksiap pakai, proses pembuatan tepung sala lauak yaitu beras dicuci dan direndam selama 12 jam, setelah itu ditiriskan hingga kering lalu dilakukan penggilingan dengan 
mesin penggiling bersamaan dengan bumbu berupa bawang putih, cabe merah, dan kunyit. Tepung selanjutnya digonseng agar menjadi kering. Satu bungkus tepung beratnya $1 / 2 \mathrm{~kg}$.

Pengolahan sala lauak yang melewati proses penggorengan dengan kadar minyak yang berlebihan,belum memenuhi kaidah kesehatan yang diharapkan dan dapat menyebabkan risiko gangguan kesehatan (Yuspa, 2016). Penyerapan minyak dalam makanan yang digoreng berkisar 4-14\% dari total beratnya (Ghidurus et al, 2010). Peningkatan kadar lemak yang disebabkan oleh penyerapan minyak pada makanan ini dapat menimbulkan masalah kesehatan seperti penyakit obesitas, kolesterol, dan jantung koroner (Meulenaer dan Camp, 2007).

Berbagai macam jajanan atau makanan yang di goreng mengandung lemak trans, diantaranya yaitu pisang goreng memiliki kadar lemak trans $2,32 \%$, ubi goreng memiliki lemak total $1,82 \%$, kroket dan tempe goreng sebesar 9,08\%, singkong goreng sebesar $2,38 \%$, dan ayam goreng tepung sebesar 2,39\% (Yuspa, 2016). Bahaya yang timbul dari banyak mengkonsumsi lemak trans yaitu Penyakit Jantung Koroner (PJK) dan tingkat kolesterol LDL yang lebih tinggi (American Heart Association; 2015; Heriansyah, 2013).

Adapun cara yang bisa dilakukan untuk menghindari resiko buruk bagi kesehatan adalah mengurangi konsumsi makanan yang mengandung lemak jenuh seperti makanan yang dimasak dengan cara digoreng dan meminimalisir proses menggoreng makanan agar gorengan aman untuk di konsumsi. Ada beberapa teknik untuk menurunkan penyerapan minyak selama penggorengan pada produk pangan, diantaranya adalah melalui penambahan komponen kimia tertentu, teknologi pemasakan (suhu dan waktu), teknik gelatinisasi, dan beberapa perlakuan pendahuluan seperti blansing, pengeringan dan edible coating atau pelapisan (Florentina, 2016).

Salah satu bahan yang digunakan untuk mengurangi penyerapan minyak yaitu tepung pragelatinisasi. Pengurangan minyak pada sala lauak bisa dilakukan dengan cara pembuatan tepung pragelatinisasi. Tepung pragelatinisasi merupakan tepung yang mengalami proses gelatinisasi dengan air ketika dipanaskan. Proses gelatinisasi ini berkaitan dengan kerusakan struktur granula pati yang menyebabkan granula pati dapat larut dalam air (Ratnayake dan Jackson, 2006).

Gelatinisasi merupakan suatu proses ketika granula pati dipanaskan dengan air yang cukup sehingga terjadi pengembangan granula pati dan menghasilkan cairan yang kental untuk memberikan kualitas produk yang diinginkan (Rohaya dkk, 2013). Proses ini terjadi pemecahan ikatan intermolekuler dari pati dengan adanya panas dan air yang digunakan dalam proses gelatinisasi menyebabkan pembengkakan granula yang tinggi dan amilosa mampu berdifusi keluar dari granula (Haper, 1981).Ketika dilakukan proses pengeringan tepung yang telah tergelatinisasi, air mudah lepas dari ikatan hidroksil sehingga kadar air sedikit menurun.

Pragelatinisasi mempunyai tiga metode, yaitu dengana memakai alat drum drying, ekstrusi dan rice cooker.Dengan drum drying, tahap pengeringan terjadi secara simultan dengan tahap gelatinisasi produk akhir yang membentuk lapisan tipis pada permukaan drum. Pragelatinisasi dengan metode ekstrusi memiliki beberapa keunggulan yang serba guna, memiliki produktifitas yang tinggi, biaya yang rendah dan dapat mengontrol derajat gelatinisasi sesuai yang diinginkan (Clerici, 2012). Metode pemasakan beras dengan rice cooker merupakan metode yang paling sederhana dan mudah diaplikasikan. Selama pemasakan, beras mengalami perubahan struktur pati, sifat fisik, komposisi kimia dan kulitas gizi. Penggunaan alat yang berbeda ini dalam proses gelatinisasi dapat menghasilkan karakteristik tepung pragelatinisasi yang berbeda (Daomukda et al., 2011).

Proses gelatinisasi ini berkaitan dengan kerusakan struktur granula pati yang menyebabkan granula pati dapat larut dalam air. Air dan suhu gelatinisasi sangat penting dalam proses gelatinisasi terutama bagaimana perubahan struktur amilosa dan amilopektin pada jumlah air dan suhu yang berbeda (Ratnayake dan Jackson, 2006). Panas dan air yang digunakan dalam proses gelatinisasi menyebabkan pembengkakan granula yang tinggi dan amilosa mampu berdifusi keluar dari granula (Harper, 1981).

Pati terdiri dari amilosa dan amilopektin. Proporsi amilosa dan amilopektin dari berbagai sumber pati berbeda-beda demikian juga dengan bentuk dan ukuran granula yang disusunnya. Umumnya, pati memiliki proporsi amilopektin yang jauh lebih besar jika dibandingkan dengan amilosa. Kandungan amilosa pada kebanyakan sumber pati biasanya berkisar antara $20-30 \%$ dan amilopektin $70-80 \%$.

Adanya perbedaan karakteristik granula pati akan sangat berpengaruh pada sifat fisik, sifat kimia, dan sifat fungsional pati. Pada struktur granula pati, amilosa dan amilopektin 
di dalam granula pati dihubungkan dengan ikatan hidrogen (Winarno, 2002).

Pati amilosa yang tinggi dapat digunakan untuk menghindari penyerapan minyak pada kudapan yang digoreng karena amilosa dapat membentuk film yang kuat (Lusas et al., 2001). Kunanopparat et al.(2001) menjelaskan bahwa adonan yang digoreng dengan kadar amilosa yang lebih tinggi membentuk kerak yang dapat menahan transfer minyak dan air sementara adonan beramilopektin tinggi tidak membentuk kerak namun mengembang selama penggorengan.

Suhu gelatinisasi pati mempengaruhi perubahan viskositas larutan pati, dengan meningkatnya suhu pemanasan mengakibatkan penurunan kekentalan suspense pati. Suhu pada saat granula pati pecah disebut suhu gelatinisasi. Menurut Winarno (2002), suhu dimana sifat birefringence granula pati mulai menghilang dihitung sebagai suhu awal gelatinisasi. Seiring mengembangnya ukuran granula pati, fraksi amilosa mulai keluar dari granula. Namun granula pati belum pecah karena masih tertahan oleh misel yang belum terganggu atau rusak oleh hidrasi air dan pemanasan.Viskositas larutan meningkat karena semakin banyak air yang terperangkap dalam granula. Hidrasi air berkelanjutan mulai merusak struktur kristalin. Rusaknya struktur kristalin menyebabkan hilangnya ikatan yang mampu menahan struktur granulapati. Proses gelatinisasi dan pengukuran viskositas pati dapat dilihat pada Gambar 1:

Sifat birefringence hilang, granula pati mulai pecah, dan viskositas larutan akan menurun. Hilangnya sifat birefringence menunjukkan gelatinisasi telah terjadi secara sempurna. Secara singkat perubahan fisik yang terjadi selama gelatinisasi adalah mengembangnya granulapati yang diiringi dengan hilangnya sifat birefringence, meningkatnya kekentalan, terlarutnya fraksi amilosa pati (bobot molekul rendah). Perubahan viskositas yang terjadi akibat pengembangan granula pati dan kelarutan makromolekul pati menjadi tahap yang penting dalam proses gelatinisasi. Ketika suhu yang diaplikasikan lebih dari suhu gelatinisasi pati, pengembangan dan kerusakan pati terjadi secara parsial.

Pengembangan sala lauak dengan teknik gelatinisasi jika dapat dikembangkan dengan baik dapat membuat produk sala lauak aman dikonsumsi, karena sala lauak tidak memiliki kadar lemak yang tinggi, sehingga mengurangi resiko penyakit berbahaya jika dikonsumsi dalam jumlah yang banyak. Penjualan sala lauak dengan teknik gelatinisasi akan mempunyai potensi yang baik untuk berwirausaha dalam bidang penjualan sala lauak yang aman dan sehat. Usaha kecil merupakan tumpuan yang diharapkan untuk mengambil strategi dengan menjadikan usaha yang mandiri, sehat, kuat, berdaya saing serta mengembangkan diri untuk meningkatkan pertumbuhan ekonomi, serta mendukung perluasan kesempatan kerja dalam mewujudkan demokrasi ekonomi.

\section{METODE}

\section{Jenis Penelitian}

Jenis penelitian ini adalah Research and Development. Menurut Sugiyono (2013) Research and Development adalah metode penelitian yang digunakan untuk menghasilkan produk tertentu, dan meningkatkan keefektifan produk tersebut.

Penelitian pengembangan menggunakan pendekatan kuantitatif dalam pengumpulan dan analisa data kuantitatif. Pada penelitian ini, pengembangan dilakukan terhadap produk sala lauak.

\section{Model Pengembangan}

Penelitian ini berupa pengembangan produk pangan yaitu pengembangan produk sala lauak. Model pengembangan yang digunakan adalah model prosedural. Model prosedural adalah model yang bersifat deskriptif, menunjukkan langkahlangkah yang harus diikuti untuk menghasilkan produk baru (Pargito, 2009)

\section{Prosedur Pengembangan}

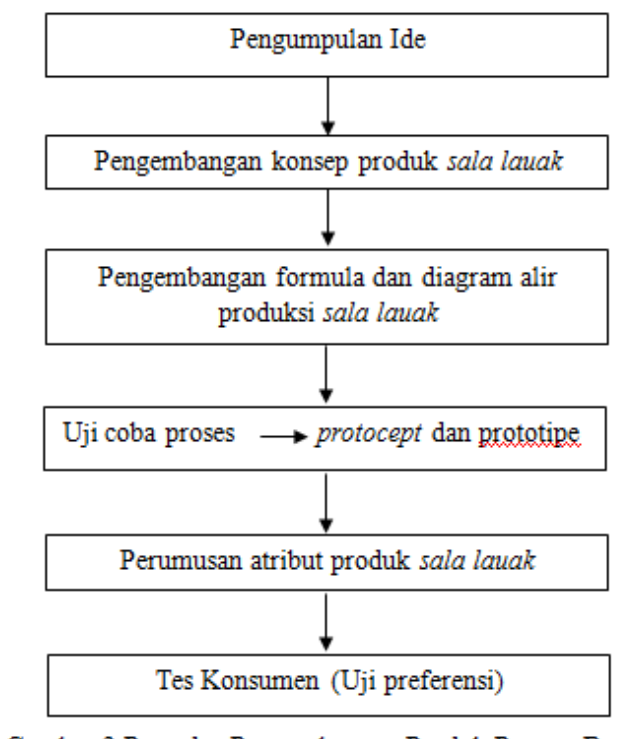

Gambar 2 Prosedur Pengembangan Produk Pangan Baru 
Kegiatan pengembangan produk pangan memerlukan tahapan sistematis yang sama dengan penelitian pengembangan pada umumnya, penelitian terhadap pengembangan produk pangan yang baru dilakukan dengan tujuan untuk menghindari kegagalan, sehingga produk baru dapat diterima secara baik oleh konsumen.

\section{Alat dan Bahan}

Alat-alat yang digunakan yaitu rice cooker, pin disc mill, kertas saring, oven pengering, timbangan, desikator, camber dan extraction unit.

Bahan utama yang digunakan yaitu beras Solok, sedangkan bahan lainnya yaitu tepung beras, ikan asin, bawang merah, bawang putih, daun kunyit , kunyit, cabe giling berah, pewarna makanan, gelatin, garam, air, minyak goreng, kertas saring dan heksan.

\section{Pembuatan Tepung Pragelatinisasi}

Proses gelatinisasi dengan rice cooker yaitu beras dan air dengan perbandingan $1: 1$ dimasak selama 15 menit. Kemudian nasi dikeringkan pada oven pengering dngan suhu $100^{\circ} \mathrm{C}$ selama 2 jam dan digiling dengan pin disc mill.

\section{Uji Coba Pengembangan}

Dalam uji coba produk sala lauak akan dilakukan pengujian oleh panelis terlatih sebanyak 5 orang. Tiga orang dari dosen tata boga PKK FPP UNP yang telah memiliki kepekaan tinggi dan pengalaman dalam produk makanan tradisional dan dua orang panelis dari pedagang sala lauak yang telah berpengalaman bertahun-tahun di dalam membuat sala lauak.

\section{Subjek Uji Coba}

Subjek uji coba akan dilakukan oleh panelis konsumen. Menurut Fitriyono (2014), panel konsumen merupakan panelis tidak terlatih yang dipilih secara acak dari total potensi konsumen di suatu daerah pemasaran yang berjumlah sekitar 30-100 orang.

Pada pengujian subjek uji coba produk sala lauak, diperlukan 50 orang panelis yang terdiri dari laki-laki dan perempuan dengan latar belakang usia yang beragam. Panelis konsumenyang akan memberikan masukannya terhadap produk tersebut, mulai dari uji deskriptif, uji deskriminatif dan uji afektif. Sehingga nantinya dapat diambil hasil dari kesukaan dan penerimaan dari penelis, apakah pengembangan produk sala lauakdapat diterima oleh masyarakat.

\section{Instrumen Pengumpulan data}

Pengumpulan data pada pengembangan produk ini dibutuhkan beberapa instrumen pengujian yaitu berupa angket pengujian pada uji deskriptif untuk menguji mutu organoleptik dari produk sala lauak.

\section{a. Instrumen Uji Deskriptif}

Format angket uji deskriptif menggunakan rating scaleuntuk menjelaskan, menggolongkan, dan menilai skala atribut dari mutu organoleptik dari pengembangan produk sala lauak yang telah diuji rangking sebelumnya oleh validator. Sehingga atribut mutu penampakan dari bentuk, rasa, aroma, tekstur dan konsistensi dapat diketahui.

\section{b. Instrumen Uji Deskrimintif (Metode Uji Rangking)}

Uji rangking adalah suatu proses pengurutan dua sampel atau lebih berdasarkan intensitas dan atribut yang dirancang menurut tingkat kesukaan suatu produk dalam memilih yang terbaik atau yang terjelek, dengan menambah atau mengurangi jumlah atribut, kualitas secara keseluruhan atau respon pada saat yang sama (Nuraini, et al., 2013).

Instrumen untuk menilai rangking produk sala lauak berupa angket pengamatan dan penilaian kualitas produk sala lauak. Dari uji rangking kelima desain percobaan tersebut nantinya ditemukan satu resep standar yang dipilih sesuai dengan rangking tertinggi oleh validator ahli.

\section{c. Instrumen Uji afektif}

Uji afektif bertujuan untuk menilai respon pribadi (kesukaan atau penerimaan) dari produk tertentu, atau karakteristik produk spesifik tertentu. Instrumen yang akan digunakan dalam penerimaan produk sala lauak ini adalah uji skala Likert. Uji skala Likert merupakan skala yang digunakan untuk menilai produk sala lauak dengan teknik gelatinisasi yang akan dikembangkan, konsumen akan memberikan penilaian dari skala "Sangat tidak suka" hingga skala "Sangat Suka" untuk mutu penampakan bentuk, warna, rasa, tekstur luar, dan tekstur dalam. Dari 
penilaian inilah nantinya akan diketahui atribut yang paling mempengaruhi preferensi konsumen terhadap produk sala lauak dengan teknik gelatinisasi

\section{Teknik Analisis Data}

a. Teknik Analisis Uji Deskriptif

Uji deskriptif menggunakan Grafik radar dalam Qualitative Descriptive Analysis (QDA).

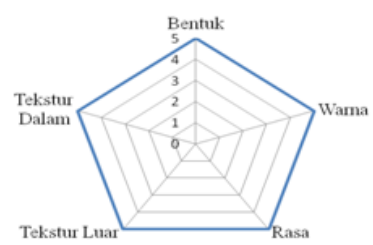

Gambar 3. Grafik radar dalam Qualitative Descriptive Analysis (QDA)

Grafik radar digunakan untuk menilai karakteristik atribut mutu sensori (organoleptik) dalam bentuk angka-angka kuantitatif. Fungsi dari uji deskriptif adalah untuk menilai mutu produk pengembangan yang baru, untuk mengetahui perbedaan antara produk pengembangan, untuk mengontrol kualitas produk makanan, dan menyediakan data sensori untuk penelitian (ISO, 2006:12-13).

\section{b. Teknik Analisis Uji Deskriminatif}

Analisis data uji deskriminatif menggunakan rumus analisis Friedmansebagai berikut :

Friedman Test

$$
T=\left(\frac{12 \sum R^{2}}{P t(t+1)}\right)-[3 p(t+1)]
$$

Hasil uji deskriminatif (uji rangking) dari protocept sala lauak menghasilkan data ordinal, karena data berupa hasil perankingan kualitas protocept sala lauak.

Metode analisis uji ranking yang akan digunakan pada penelitian ini adalah analisis Friedman, dimana data hasil penilaian ranking sampel resep sala lauak akan diurut perolehan ratarata nilai tertinggi, yaitu sampel dengan ranking pertama yang menunjukkan kualitas terbaik. Dari nilai rata-rata tiap sampel yang diuji coba, dihitung dengan rumus diatas untuk mengetahui perbedaan kualitas produk. Selanjutnya hasil analisis uji rangking ini akan dinilai kualitas atribut mutu organoleptiknya pada uji deskriptif.

\section{c. Teknis Analisis Uji Afektif}

Metode uji afektif adalah metode yang digunakan untuk mengukur sifat subjektif konsumen terhadap produk berdasarkan sifat-sifat sensori. Hasil yang diperoleh adalah penerimaan (diterima atau ditolak), kesukaan (tingkat suka atu tidak suka), dan pilihan (pilih satu dari yang lain) terhadap produk.

Teknik analisis uji afektik memakai analisis konjoin. Metode konjoin merupakan teknik yang sangat baik untuk menjawab dua pertanyaan yaitu bagaimana kepentingan sekumpulan atribut dan dalam pengembangan produk baru sekaligus model produk mana yang paling disukai dan diminati oleh para konsumen (Aaker, 2014:65).

Menggunakan analisis konjoin pada uji preferensi konsumen terhadap produk sala lauak dengan teknik gelatinisasi dilakukan dengan tujuan agar mengetahui kegunaan dari setiap taraf atribut yang diujikan. Analisis ini akan menunjukkan pengaruh mutu terhadap kesukaan konsumen. Pada penelitian ini, analisis data preferensi konsumen dilakukan dengan menggunakan softwarePASW Statistic 18.0 .

\section{d. Analisis Jumlah Lemak}

Metode yang akan dilakukan untuk menguji penyerapan minyak pada produk sala lauak adalah metode Ekstrasi Langsung, dengan alat Soxhlet. (SNI 01-2891-1992).

\section{HASIL DAN PEMBAHASAN}

1. Tahap Pengumpulan Ide dalam Melakukan Pengembangan Terhadap Produk Sala lauak dengan Proses Teknik Gelatinisasi.

Pada tahapan ini, data diperoleh dari hasil wawancara dan observasi yang dilakukan di Ulakan Kecamatan Nan Sabaris, Kabupataen Padang Pariaman. Sehingga menumbuhkan ide untuk melakukan pengembangan sala lauak dengan teknik gelatinisasi untuk mengurangi kadar lemak yang terkandung.

Pengembangan sala lauak pada penelitian ini memakai metode rice cooker. 
Pemasakan nasi dengan rice cooker merupakan metode yang tidak asing bagi masyarakat dan yang paling mudah dilakukan. Untuk metode drum dryer dan twin screw extruder merupakan metode yang sulit diterapkan di masyarakat kerena keterbatasan alat yang susah untuk didapatkan.

2. Pengembangan Konsep produk Sala lauak dengan Proses Teknik Gelatinisasi

Perancangan sala lauak dilakukan dengan memodifikasi bahan utama yaitu tepung beras menggunakan teknik gelatinisasi dengan metode rice cooker. Pembuatan tepung beras gelatinisasi sangat mudah untuk dilakukan. Pertama masak beras terlebih dahulu selama 15 menit dengan perbandingan beras dan air $1: 1$, setelah itu beras ditiriskan lalu masukan ke dalam oven pengering dengan suhu $100^{\circ} \mathrm{C}$ selama 2 jam, setelah itu giling beras dengan disc mill.

Sala lauak dengan teknik gelatinisasi juga memberikan penambahan bahan, yaitu gelatinsebanyak $1 \%$ dari jumlah tepung. Bubuk gelatin menghasilkan gel yang berfungsi untuk pengikat sehingga membuat tekstur luar pada sala lauak yang memakai tepung beras dengan teknik gelatinisasi menjadi renyah.
3. Pengembangan Formula Dan Diagram Alir Proses Produksi

Pengembangan formula dilakukan melalui desain percobaan dari resep sala lauak melalui perancangan dan analisis variasi jumlah penggunaan bahan. Pengembangan formula pada resep ada dua bagian. Resep I digunakan untuk kontrol positif dengan penggunaan tepung beras biasa dan resep standar sala lauak. Resep II digunakan untuk sampel dengan penggunaan tepung beras gelatinisasi dan modifikasi resep.

Dua desain resep ini masing-masing dilakukan tiga kali pengulangan dengan Resep I untuk kode sampel SK001, SK002, dan SK003 dan Resep II untuk kode SS001, SS002, dan SS003. Masing-masing resep menggunakan jumlah bahan yang sama kecuali pada Resep II yang menggunakan air $100 \mathrm{~mL}$ lebih banyak dari resep kontrol. Pada rasa sala lauak untuk resep II ini ditambahkan $40 \mathrm{~g}$ ikan asin lebih banyak, karena standar resep sala lauak tidak terlalu terasa ikan asin. Pada sala lauak untuk resep II ditambahkan kunyit lebih banyak menjadi $4 \mathrm{~g}$ dan cabe giling menjadi 50g..

Tabel 1. Desain Percobaan Resep Sala Lawak

\begin{tabular}{llll}
\hline No & \multicolumn{1}{c}{ Bahan } & & Perlakuan \\
\hline 1 & Tepung beras & 500 & II \\
2 & Tepung Beras Gelatinisasi & - & 500 \\
3 & Gelatin & - & 5 \\
4 & lkan Asin & 40 & 80 \\
5 & Bawang Merah & 12 & 20 \\
6 & Bawang Putih & 24 & 28 \\
7 & Daun Kunyit & 8 & 10 \\
8 & Kunyit & 4 & 8 \\
9 & Cabe Giling & 40 & 50 \\
10 & Pewarna Makanan & - & $1 / 2$ sdm \\
11 & Garam & 4 & 4 \\
12 & Air & 1000 & 1500 \\
13 & Minyak Goreng & 1000 & 1000 \\
\hline
\end{tabular}

4. Uji Coba Proses Untuk Menghasilkan Protocept dan Prototipe

a. Data uji deskriptif produk sala lauak oleh validator
Nilai rata-rata pada uji deksriptif untuk sampel kontrol (SK) adalah sebagai berikut: 
Tabel 2. Rata-rata Uji Deskriptif Sampel Kontrol (SK) Sala Lauak

\begin{tabular}{ccccccc}
\hline \multicolumn{2}{c}{ Karakteristik Organoleptik } & Bentuk & Warna & Tekstur Luar & Tekstur Dalam & Rasa \\
Validator & & & & & \\
\hline \multicolumn{2}{c}{} & & & & 3,33 & 3,67 \\
& Validator 1 & 3,00 & 3,67 & 3,00 & 3,67 & 4,00 \\
& Validator 2 & 4,00 & 4,00 & 3,33 & 3,67 & 4,00 \\
& Validator 3 & 3,00 & 3,67 & 3,00 & 3,67 & 4,67 \\
& Validator 4 & 2,67 & 3,67 & 3,67 & 3,33 & 4,33 \\
& Validator 5 & 3,00 & 3,67 & 3,33 & 3,59 & 4,13 \\
\hline
\end{tabular}

Nilai rata-rata pada uji deksriptifuntuk

sampel (SS) adalah sebagai berikut :

Tabel 3. Rata-rata Uji Deskriptif Sampel (SS) Sala Lauak

\begin{tabular}{lllllll}
\hline Validator & Karakteristik Organoleptik & Bentuk & Warna & TL & TD & Rasa \\
\cline { 1 - 5 } & & & & & \\
& Validator 1 & 3,00 & 4,33 & 3,33 & 3,67 & 4,00 \\
& Validator 2 & 4,00 & 4,00 & 3,67 & 3,33 & 4,00 \\
& Validator 3 & 2,67 & 3,67 & 3,00 & 3,00 & 3,67 \\
& Validator 4 & 3,67 & 4,30 & 4,33 & 4,33 & 4,33 \\
& Validator 5 & 3,67 & 3,67 & 4,00 & 4,00 & 4,67 \\
& Rata-rata & 3,40 & 3,99 & 3,67 & 3,67 & 4,13 \\
\hline
\end{tabular}

b.Data uji rangking produk Sala lauak

Berdasarkan uji rangking pada sampel uji coba rancangan produk sala lauak oleh para ahli, diperoleh data sebagai berikut :

Tabel 4. Hasil Uji Rangking Resep Sala Lauak

\begin{tabular}{ccccccc}
\hline Sampel & SK001 & SK002 & SK003 & SS001 & SS002 & SS003 \\
Validator & & & & & & \\
\hline Validator 1 & 3 & 3 & 4 & 3 & 3 & 3 \\
Validator 2 & 3 & 4 & 4 & 3 & 3 & 4 \\
Validator 3 & 1 & 4 & 3 & 1 & 3 & 3 \\
Validator 4 & 2 & 3 & 3 & 2 & 3 & 4 \\
Validator 5 & 1 & 2 & 3 & & & \\
\hline
\end{tabular}

\section{a. Uji Preferensi Konsumen}

Setelah pengujian terbatas oleh validator, maka prototype sala lauak diujikan lagi kepada konsumen bebas untuk mengetahui tingkat kepentingan atribut mutu yang lebih mempengaruhi preferensi konsumen serta rancangan stimuli sala lauak yang lebih disenangi oleh konsumen. Sampel yang digunakan adalah sampel SS003 yang merupakan sampel dengan rangking tertinggi untuk produk berbahan tepung pregelatinisasi.

Tabel 5. Importance Values

\begin{tabular}{lr}
\hline BENTUK & 17,465 \\
WARNA & 16.449 \\
TL & 18,340 \\
TD & 29,484 \\
RASA & 18,261 \\
\hline
\end{tabular}


Berdasarkan hasil analisis konjoin dari data preferensi konsumen, maka dapat dijabarkan hasil analisisnya adalah dari segi bentuk, karena utility sangat suka positif, maka secara umum responden sangat menyukai dengan bentuk sala lauak. Kemudian dari segi warna, karena utility suka positif,maka secara umum responden suka dengan sala lauak yang diujikan. Dari segi tekstur luar, karena utility suka mempunyai nilai positif, maka konsumen menyukai produk sala lauakyang diujikan.

Nilai utility tekstur dalam bernilai positif yang berarti konsumen menyukai sala lauak yang diujikan. Sedangkan dari segi rasa, karena nilai utility sangat suka positif, maka responden sangat menyukai produk sala lauak.

\section{b. Pengukuran Predictive Accuracy dan Uji Signifikansi : \\ Pada Output Korelasi (untuk} mengukur Predictive Accuracy), terlihat baik angka korelasi untuk Sampel maupun Holdout adalah tinggi (0,945 dan 0,857), dengan signifikansi yang tinggi $(0,000$ dan 0,001 yang dibawah 0,05). Bisa dikatakan bahwa pendapat konsumen terhadap produk sala lauak tersebut bisa diterima untuk menggambarkan keinginan populasi pembeli sala lauak.

Kesimpulan dari hasil uji kojoin adalah responden rnempunyai ketepatan akurasi yang tinggi dan signifikan. Maka bisa disimpulkan bahwa responden untuk sampel produk sala lauak pada dasarnya menilai bahwa produk yang diujikan memiliki bentuk yang sangat bagus, warna yang sesuai dengan keinginan konsumen yaitu kuning keemasan, tekstur luar yang renyah, tekstur dalam yang lembut, dan rasa ikan asin yang sangat terasa untuk sala lauak.

\section{Penentuan Kadar Lemak}

Penentuan kadar lemak pada produk sala lauak yang akan diuji laboratorium menggunakan sampel yang telah ditentukan oleh validator dari aspek kualitas yang terbaik. Dimana sampel yang diuji kualitas lemak ini merupakan sampel yang ketiga SS003 dan telah menemukan standar resep yang paling baik. Penentuan kadar lemak dalam produk sala lauak telah dilakukan dengan metode sokletasi di Laboratorium Instrumen Dasar, Fakultas Teknologi Pertanian, Universitas Andalas. Dari uji tersebut didapat hasil sebagai berikut :

Tabel 6. Hasil Uji Kadar Lemak Produk Sala lauak

\begin{tabular}{ccccc}
\hline No & Sampel & Bentuk & Parameter & Hasil (\%) \\
\hline 1 & Kontrol (SK) & Padat & Kadar Lemak & 25,0 \\
2 & Sampel (SS) & Padat & Kadar Lemak & 7,4 \\
\hline
\end{tabular}

\section{PENUTUP}

Dari uraian diatas penulis dapat menarik kesimpulan sebagai berikut:

1. Pengembangan Sala Lauak dengan Teknik Gelatinisasi Terhadap Penyerapan Minyak

Pengembangan produk sala lauak menggunakan tepung gelatinisasi berhasil dilakukan yang diuji secara evaluasi sensori oleh validator dan panelis konsumen. Berdasarkan uji tersebut sala lauak dengan tepung gelatinisasi memiliki nilai tinggi dan banyak disukai oleh validator dan konsumen. Penambahan gelatin $1 \%$ pada adonan berhasil dilakukan untuk memperbaiki tekstur luar salalauak agar menjadi renyah. Dan pemberian pewarna makanan diberikan sebanyak $1 / 2 \mathrm{sdm}$ agar produk sala lauak memiliki warna yang baik.

2. Mutu Organoleptik Pada Produk Sala Lauak Dengan Proses Teknik Gelatinisasi

Berdasarkan nilai rangking sampel secara keseluruhan yang memiliki mutu organoleptik yang tinggi oleh validator adalah sampel SS003 yaitu sala lauak dengan tepung teknik gelatinisasi. Kualitas produk sala lauak dengan penggunaan tepung gelatinisasi pada sampel SS003 berpengaruh signifikan terhadap bentuk, warna, rasa dan tekstur sala lauak sampel SK003 dengan nilai yang lebih rendah.

Berdasarkan nilai rangking sampel secara keseluruhan yang memiliki mutu organoleptik yang tinggi oleh validator adalah sampel SS003 yaitu sampel yang menggunakan tepung beras gelatinisasi dengan nilai 4,4. Hasil uji validator dan preferensi konsumen menghasilkan nilai yang signifikan terhadap atribut bentu, warna, tekstur luar, tekstur dalam, dan rasa dari sala lauak.

3. Kadar Lemak Terhadap Produk Sala Lauak dengan Proses Teknik Gelatinisasi.

Penurunan serapan minyak pada sampel yang menggunakan tepung 
pregelatinisasi berhasil dilakukan dengan serapan minyak sampel tepung pragelatinisasi (SS) $70,4 \%$ lebih rendah dibandingkan dengan penyerapan minyak sampel dengan tepung beras (SK)yaitu $25 \%$.

Adapun saran yang dapat disampaikan penulis dalam penelitian ini antara lain:

1) Bagi peneliti lain agar dapat melakukan pengembangan terhadap tepung pragelatinisasi sehingga dapat menambah kesempurnaan untuk produk sala lauak yang lebih baik lagi.

2) Bagi penjual sala lauak agar bisa memakai tepung pragelatinisasi untuk pengurangan minyak.

3) Disarankan kepada penderita penyakit seperti obesitas, kolesterol dan jantung koroner agar mengkonsumsi sala lauak dengan teknik gelatinisasi.

4) Hasil penelitian ini dapat dijadikan rujukan oleh peneliti lanjutan sebagai pengembangan produk makanan tradisional lainnya.

\section{DAFTAR PUSTAKA}

American Heart Association, 2015. Facts Taking the Trans Fat Out Banning Trans Fats in Schools, Workplaces, and Restaurants.

(www.heart.org/policyfactsheets) diakses 20 Juli 2018.

Aorora. (2008). "Lamak Bana". http:/kbaspariaman lamakbana.wordpres s.com. Diakses tanggal 10April 2018.

Clerici, M. 2012. Physical and/or Chemical Modifications of Starch by Thermoplastic Extrusion.

http://cdn.Intechopen.com/pdfs/34060/In TechPhysical_and_or_chemical_modific ations_of_starch_by_thermoplastic_extr usion.podf. Dakses pada [20 April 2018].

Daomukda, N, Moongngarm. 2011. "Effect of cooking methods on physicochemical properties of brown rice. International
Conference on Environmental Science and Technology"IPCBEE Vol. 6, IACSIT Press, Singapore.

Ghidurus, M.; M. Turtoi; G. Boskou; P. Niculita \& V. Stan.(2010). Nutritional and Health Aspects Related to Frying (I). Romanian Biotechnological Letters Vol.15( 5).

Harper, J.M. 1981. "Extrusion of Food" Volume I.CRC Press, Inc Boca Raton-Florida.

Lusas , Raymond W. \& Lloyd W. Rooney. 2001. Snack Foods Processing. Washington D.C.: CRC Press.

Nuraini dkk. 2013. Petunjuk Praktikum Evaluasi Sensori. Program Studi IImu dan Teknologi Pangan, Purwokerto.

Pargito, 2009. Penelitian dan Pengembangan Bidang Pendidikan, Jurusan Pendidikan IPS Universitas Lampung. Bandar Lampung.

Ratnayake WS, Jackson DS. 2006. Gelatinization and Solubility of Corn Starch during Heating in Excess Water: New Insights. Journal of Agricultural and Food Chemistry 54 (10).

Rohaya, M.S. masket, dkk. (2013). Rheological properties of different degree of pregelatinized rice flour batter. Sains Malaysia 42: 1707-1714.

Shih, Fred F., dan Kim W. Daigle. 2002. Preparation and Characterization of Low Oil Uptake Rice Cake Donuts. Cereal Chem (79) 5: 745-748.

Sugiyono, (2013). Metode Penelitian Kuantitatif Kualitatif dan $R \& D$. Bandung. CV Alfabeta.

Yuspa, Hanum. 2016. "Dampak Bahaya Makanan Gorengan Bagi Jantung". Keluarga Sehat Sejahtera, Vol 14 (28) 